\title{
The best poem in Vahshi Bafghi's point of view is not the most false one
}

\author{
Seied Mohammad Bagher Kamaladdini \\ Department of Persian Literature and Language, Payame Noor University, Tehran, Iran \\ E-mail address: kamaladdini@pnu.ac.ir
}

\begin{abstract}
Knowing about poem particulars of Kamal Addin Vahshi Bafghi and his thoughts needs further investigation and research in universities. Vahshi's love, affection and frenzied is unique in the world. without doubt if he was not a real lover and love's fire was not in his heart, he couldn't have such an effective poems and his speech was not so painful and vexing. The secret of his Artillery and flaming speech just is inside his broken heart and his anguish. He mentioned about moralities like modesty in a very attractive way and high sensitiveness and used marvelous expressions, so it is in an exclusive and recent form. There for Vahshi's method is what one could forget the idea: the best poem in Vahshi's point of view is the most false one. His speech is sincere and candid, so listeners rely on it and finally his poem is extremely according to his feelings, thoughts and conscience since it comes from his soul, goes into one's heart! This article is an accurate study in Vahshi's poems specially his love poems and lyrics, was done by descriptive methods and the application of library resources.
\end{abstract}

Keywords: Vahshi's Bafghi; Love; Poem; Reality; Heart

\section{INTRODUCTION}

Review from the perspective of literary works can be described as a life lesson. With the breadth and variety of features and its manifestations. Literature links the two passages we live with. The emotional one when we read it, the wisdom passage reveals, when we review it. When we read the poem, the poet's emotions and feelings, and our emotions have common aspects with his mental attunement, we find Quote "Andre Moura" We will be in contention event that the moments of our lives with that incident, have Combination in these cases, our spirit and soul, cannot be dismissed interact (Anvari - Shoar, 1993, 7)

Aspects of speech or expression analysis of imagery in a literary work can highlight the hidden aspects that influence the effectiveness of Expressive elements such as simile, metaphor, allusion and literary scholars and critics considered by legitimate literary workers.

The reader of Vahshi's lyrics with imagery rather not face, but finds a way to keep Vahshi poetry of imagery, metaphor and imagery that does not see everything unreal here is a tale of true love the reader to believe that it is Vahshi's poem that sits on hearts and is 
accepted. In writing this article, the author does not go much further sources familiar with the Vahshi lyrics and tried to analyze what is at the heart of the text of the Vahshi lyrics, it makes the study tangible and obvious. Thus, the methods are analytical - descriptive with the use of library resources.

\section{About Vahshi}

Vahshi Kamal Addin Bafghi is one of the proficient poets in the tenth century. We cannot trust properly on his birthday. Abdalnabi-Fakhr Alzamani, has written TazkereMeykhane (a biography) said that he died at age 52 years. As Molla Ghotb-Shadebaff said: Nightingale in flower garden of curtsey closed lips $=991$, because his death date is certain, so his birth date is 1594, and there is no other way to know the date of his birth. (Nafisi, 1985, 15). During Vahshi's life, three strong government rulers: Gurkanyan in India, in Othmani legal Ismail Shah and Shah Tahmaseb Safavid in Iran, in terms of political, economic and social conditions of his time were influential. The frenetic life of the renowned poet and great orator in the tenth century, was contemporaneous with the reign of Shah Tahmaseb and, Shah Ismail Safavid, and the eldest son of Shah Tahmaseb, Shah Mohammad Khodabandeh.

What remains to this day from Vahshi poems and comes to us is the following: the lyrics, odes, tracks, composition clauses, rather than dams, Quatrain, scattered Masnavies and three Masnavies: Khold e Barin, Nazer and Manzoor, and Farhad and Shirin.

\section{Vahshi lyrics style}

Vahshi verse literally, wording style, the word build combinations is close to Hindi lyrics style. Music composition and specific application quality in terms of Hindi poets distinguish the style from other styles. In Vahshi poetry it can be felt, There for Vahshi's speech is similar to the spoken language. Words such as: inconsiderate, ungenerous, inattentive, cause, need, now, and market are very close to our modern terminology and Less has been used in previous works. Vahshi's speech is the people's language but according to poet's education, his speech is literary and at the same simplicity and proximity, it is not equal to market's language and there are not in the same level.

Terms and compounds such as: careless insane, exciting love, cruel mistress, sweet heart, alien burner, seizing one by collar and... Hindi and the effect and popularity of it, affected Vahshi's poem and one could imagine it easily:
A dusty Vahshi's face comes like Tornado
Where does this carless insane come from?
Cruel love seize me by the collar
The tailor has difficulties with my torn collar
My alien burner sweetheart, cruel mistress
If you made me familiar what should I do then?
(Vahshi's poetical book 1960, 11-19)

Sometimes in Vahshi's lyrics we find some proximity to Hindi style like:

\footnotetext{
Because of my bad luck chaff escapes from amber Instead of leaf our tree makes dagger The poison of regretful is something we took under soil This grass that grows from our gravesite (The same source:12)
} 
Another common point of his poetry whit Hindi style is heavy weights in lyrics, but the number of lines are shorter than Hindi style.

Hindi's also poetry are different from Vahshi's lyrics in thought and way of thinking. There isn't any attention to love in Hindi's lyric, but it is the only importance in Vahshi's speech. Love is the foundations of Vahshi's lyric. Vahshi's lyric are not only containing: advice, wisdom, philosophy, mysticism, but he paid attention to lyric's mission and it's love according to lyric's meanings.(The same source:21).

The actual inflammation in Vahshi's speech and poetry made up ordinary people to accept it. Since he such as some storytelling lyricism and some poets who praise something or somebody has not dabbled in poetry. he is a crazy flaming lover who tells the story of his broken heart and expresses his sympathy with short lyrics, in such a way that apparently none of Iranian lyricism has not such a familiarity with earthly love.

This great poet of the tenth century, because of avoiding mind digression didn't use adornment obviously, though had enough possession in literary. Only he used beautiful figures of speech and spoke about a flaming love and amorous qualifications. he adorned his poem in such a method and never was extravagant, so his poem is very simple and natural.

He expressed many moral issues, like modesty and humility with beautiful allegories so it became tangible and unique.

So Vahshi's poetry make our mind to be forgotten this idea that the best poetry is the most false one. His speech is heartfelt and without mask, so the listener truly trust, and ultimately, his poems are according to his feelings and conscience, since it comes from his soul, goes in to one's heart.

Vahshi's poetry from Psycho lyrics point of view is called a free-thinking person the poem is trying to avoid poetry imitations and to be new and modern, since the genuineness of poem is its indicator; being fresh and miscellaneous is delightful, if it were true not false, (Zarrinkoub, 1977, p 16)

The Themes of Vahshi Bafghi's poem, mainly including: love, praise and worship, and mourn, the elegy, satire and abuse that among these the main part of his Poems is love.

Vahshi's love, infatuation, burner and heart rending feelings is unique in the world. Undoubtedly if he wasn't a real lover and lost heart, and his heart wasn't so broken and exhausted so this hidden fire wasn't so strong he couldn't say these pathetic, fiery, heartrending and painful, words and the secret of his speech is just his anguish and they are effective because of coming from his flaming heart.

Vahshi's love is a diagram of risking all in gambling and his speech is the language of doleful people. There is no listener who does not pay attention to his tender words and has no feelings and one's sorrows couldn't be awake. In fact, the best part of the Vahshi's poem is his lyrics which are so pathetic and amorous. Hosein Nakhaiee who brought 397 lyrics of Vahshi in his poetical book noted: they are the most beautiful reminiscence of Vahshi Bafghi (Nakhaiee, introduction Vahshi's poetical book, 1960: 87).

Pathetic and sad words that Vahshi left in the beginning of "Farhad and Shirin" and requested an afflicted heart and inflammable chest, is truly the golden leaf and rare in literary, Vahshi's speech is unique in recognizing true love and praising of God's power.

According to Vahshi's point of view the foundation of everything in the world is love, and as we have seen, in all of the world anything isn't empty of this desire and he knew the universe as a "parasite of love".

The universe is as a parasite of love

Love is because of grace's domination and desire's extension 


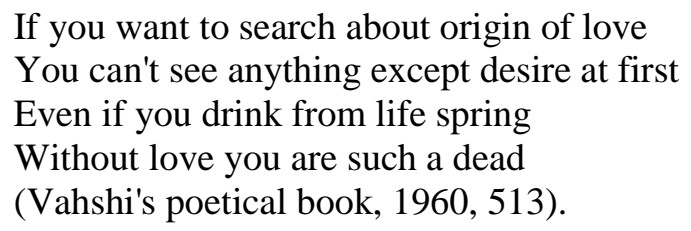

The main theme of the most commonly used words in the Vahshi's poetry, especially the lyrics of the poetical book, the word love is that combines the following ways:

Shrine of Love, King of Love, King of Love, alchemy of love, lasso of love dice love wine, love, love the sea and ...

Of course, the Vahshi Bafghi lyrics and lyrical poetry of Rudaki and his contemporaries similarities seen, So that we can restore Vahshi Bafghi Khorasani style ones, which unfortunately did not join in time he realized it was two centuries action. (Molla ahmad, 1998, 43)

\section{CONCLUSION}

After investigation in Vahshi Bafghi's poetry, we can conclude that he wasn't eager to use of imagery and simply states are the main characteristics of his oratory style. Also some words are frequently used. These words are common in Vahshi's lyrics and the main focus of them is on love. But the basic point about his poetry is: "the most real one is the most beautiful".

\section{References}

[1] Anvari Hasan, Shoar Jafar (1993). Razmname (NCC letter) of Rostam and Esfandyar, Tehran, Elmi publication.

[2] Zarrinkoub Abdolhosein (1977). Poetry without mask and Lie, Tehran, Javidan publication.

[3] Molla Ahmad Mirza (1998). Human literature culture Adib publication, Dushanbe (Tajikistan).

[4] Vahshi Bafghi, Kamal Addin (1960). Poetical book editor: Hosein Nakhaiee, Tehran, Amir Kabir publication, first edition.

[5] Vahshi Bafghi, Kamal Addin (1985). Poetical book by Saeid Nafisi, Tehran, Jvidan publication.

[6] Seyed Mohammad Bagher Kamaladdini, International Letters of Social and Humanistic Sciences 10(1) (2014) 20-25.

[7] Ayoob Moradi, Mahmoud Kamali, Sara Chalak, Hooshang Izedi, International Letters of Social and Humanistic Sciences 13 (2014) 32-51.

[8] Mohammad Baqere Kamaladdini, Morteza Ghiasi, International Letters of Social and Humanistic Sciences 15(1) (2014) 22-30. 
[9] Seyed Mohammad Bagher Kamaladdini, International Letters of Social and Humanistic Sciences 15(2) (2014) 119-124.

[10] Seied Mohammad Bagher Kamaladdini, International Letters of Social and Humanistic Sciences 16(2) (2014) 194-201. 